\title{
Preference stability and memory: two unlikely companions
}

\author{
Silvio Aldrovandi ${ }^{*}$ and Daniel Heussen ${ }^{2}$ \\ 1 Department of Psychology, University of Warwick, Coventry, UK \\ 2 Department of Psychology, University of Leuven, Leuven, Belgium \\ ${ }^{*}$ Correspondence: s.aldrovandi@warwick.ac.uk
}

Do people have stable risk preferences? This important question has engaged normative (von Neumann and Morgenstern, 1947) and both computational (e.g., Kahneman and Tversky, 1979, 1992; Tversky and Koehler, 1994; Birnbaum, 2008) and non-computational descriptive theories of judgment and decision-making (e.g., Brandstätter et al., 2006). The above theories differ, among other aspects, in how they conceptualize decision-making in general and risk preferences in particular. For instance, decisionmaking under uncertainty has been thought of as either a rational process through which an agent maximize "utility" (the perceived goodness of an option) or a process that translates objective, external utility into stable internal, subjective value. The stability (or instability) of risk preferences emerges as a by-product of such processes and conceptualization.

Here we would like to take a step back and consider the question from a different angle. A discussion about preference stability raises the question: where does the stability come from? If we start with the assumption that people have stable risk preferences, which cognitive processes underlie stable risk preferences? One obvious candidate for the origin of preference stability is memory. We need to rememberto some level or other - that we like something (e.g., wine) so to be able to prefer it to something that we like less (e.g., cider). In order to be able to make a choice between two options we at least need to be able to keep both options in short-term memory (STM) for long enough to make the decision. From a more long-term perspective the choices we have made - and tend to make - need to be remembered in order to reduce or avoid cognitive dissonance (Festinger, 1957) and develop a sense of self. LeDoux $(1996,2002)$ argues that the self is a representational structure emerging from integrative memory processes. We are one because our memory holds the pieces together, and it lets us integrate in the myriad of experiences we have, the things we see and the aspirations we have. Memory influences decision-making even when judgments are made "on-line" (i.e., while experiencing the to-be-assessed experience) and relying on memory becomes a relatively costly cognitive process (Aldrovandi et al., 2009, 2011; for a review, see Hastie and Park, 1986). Accessibility - the influence of the most easily retrievable information on judgment (e.g., Kahneman and Tversky, 1979) - is so ubiquitous in its influence on judgments and decision tasks, that it is generally considered as a truism (cf. Schwarz and Vaughn, 2002). Most approaches and models therefore include memory processes amongst the cognitive precursors of judgment biases (e.g., Dougherty et al., 1999; Stewart et al., 2006; Weber and Johnson, 2006).

Thus, if we accept the claim that memory has a strong influence on judgments and decision-making, the question is then whether memory processes sustain the stability of our preferences across situations, contexts, and stimuli? We feel that the answer to this question is a resounding "no." In a nutshell, our memories are not stable, they are influenced by motivational and situational factors and they are highly malleable and changeable. Memory formation, encoding, and retrieval are susceptible to bias and it is increasingly accepted that affective states are highly reconstructive (e.g., Kemp et al., 2008). In this opinion letter, we will make three observations on why memory cannot sustain stability for risk preferences. First, we will discuss how memory biases how we summarize the quality of recent experiences - hence influencing our choices and leading to preference instability. Second, memories for our preferences are highly distorted and highly reconstructed - do we really remember what we prefer or do we prefer what we chose? Third, we will reflect on how long-term memory (LTM; what we know) influences STM (short-term memory; what we remember from a recent experience) "filling in the gaps" and hence potentially decreasing the correspondence between experience and choice.

Let's start with the discrepancy between experienced and remembered utility. How we summarize the quality of an experience can be very different from what we actually experienced. The work by Kahneman and colleagues suggests that how people summarize experiences in hindsight drives the choices they will make in the future; for instance, retrospective evaluations appear to be an important input into decisions to repeat (or not repeat) past experiences (e.g., Kahneman et al., 1993; Kahneman, 2000; Kahneman and Thaler, 2006). In medical settings, this influence of our memory can lead people to take bad choices and increase risk-taking. For instance, a large proportion of women who do not attend routine mammogram screening mention the remembered pain of previous screenings as the reason for their decision (Baines et al., 1990; Elwood et al., 1998). More strikingly, about $40 \%$ of patients who survived a cardiac arrest decide not to undergo future revival procedures - and again this choice was largely due to the remembered discomfort of the treatment (Bedell et al., 1983). However, would people always take these risks? Evidence suggests that the same category of unpleasant and/or painful medical procedures can be remembered very differently, and that decisions about these can largely differ as a consequence. In an oftcited clinical study, Redelmeier et al. (2003) showed that adding an extra period of pain can actually improve the evaluation of a painful medical procedure. Patients undergoing colonoscopy were randomly assigned to either a control group, who underwent the standard procedure, or an experimental group. In the latter condition, the procedure was extended by leaving the apparatus in place for an average $2 \mathrm{~min}$ after the clinic examination was completed. This added experience was mildly uncomfortable - but 
less painful than the preceding moments. As a result, the experimental group rated the colonoscopy as a whole as less painful than patients in the control group; the authors argued that this result was due to the final moments (recency in memory) being largely overweighed. Confirming the link between memory and decisionmaking, the patients from the experimental group were more likely to comply with screening recommendations - and hence less likely to take the risky decision of forgoing future screening. On the same principle, Aldrovandi et al. (2011) showed that simply inserting a 10-s interval between items presentation and evaluation largely reduces the impact of a negative word on the pleasantness rating for the list as a whole. A subsequent recall task showed that memory functioning was responsible for these evaluations - as the delay effect on judgment was mediated by the drop in recall for the recency item (e.g., Bjork and Whitten, 1974). One could argue that memory biases retrospective evaluations only with affective and experiential stimuli, where it is possibly arduous to "extract" utility for each segment of the to-be-assessed experience. However, similar biases have also been observed with monetary sequences (pay outs; Langer et al., 2005), where one would expect affect to play less of a role and utility maximization to have a stronger effect. As a final and related point, preferences depend also on temporal proximity. The temporal proximity hypothesis (Soman, 2003) states that early (late) negative instances lower prospective (retrospective) evaluations more than late (early) ones. When evaluating an unfolding event, either primacy-for prospective evaluations - or recency effects - for retrospective ones - are observed.

Our memories for our preferences are distorted and highly reconstructed - more in hindsight to justify the decisions than with foresight to determine what decisions we will take. Indeed, once a choice is made, how aware are people of the reasons that drove their decision-making? How much correspondence is there between the reasons that influence decision-making and those reported in retrospect? If people "construct" (cf. Shafir et al., 1993) reasons in order to make a decision, it could be argued that such reasons are available after an option is selected (or rejected). Recent evidence seems to suggest that people can be rather inaccurate in this respect. When thinking back about a choice scenario, it seems that people justify their decisionmaking depending on what they believe their choice was - rather than their actual choice (Johansson et al., 2005; Henkel and Mather, 2007). Strikingly, people can go a full length in order to justify a choice they actually did not make, but were made to believe they did (Johansson et al., 2005). This meta-cognition inaccuracy about decisions seems also to influence memory for the features of the options in the choice scenario. Henkel and Mather (2007) showed that positive features are more likely to be remembered as associated with the chosen option - regardless of it being true or not (see also Brehm, 1956). Potentially, fuzzytrace theory (FTT; Brainerd and Reyna, 1992) offers a memory-based theoretical framework to explain this apparent dissociation between recall and judgment and why people can be so inaccurate when thinking back about their decision-making. According to FTT, encountered information is encoded in two parallel - and independent - ways. On the one hand verbatim information includes item-specific and episodic aspects of the information. On the other hand, people encode a gist, a "general picture" of the information where the specific details are somehow more blurred. As these two different forms of representation are encoded, stored, and retrieved in an independent manner, dissociations can be easily observed. In the context of decision-making, if we assume that people make choices mostly on the basis of the gist they encode about the choice scenario, then it can be explained how they can be so inaccurate about its verbatim information (a similar approach is that of the value-account; Betsch et al., 2001). To sum up, memory for our preferences is highly distorted and reconstructed - and these qualities make preferences highly unstable. Also, preferences are functional in that they can be used in hindsight to justify the decisions taken; this means, though, that preferences themselves are not always accessed to determine our decision-making. Decisions are then vulnerable to situational and contextual factors, and instability in decision-making under uncertainty is readily explained.

The influence of LTM on current task performance has been demonstrated extensively in research on false memories (e.g.,
Roediger and McDermott, 1995; Norman and Schacter, 1997; McDermott and Watson, 2001). More recently, studies have shown similar effects of LTM on episodic and STM in the visual domain (Hemmer and Steyvers, 2009; Heussen et al., 2011). When people are asked to reproduce the size of an apple that they have seen a few seconds ago, they are influenced both by the average size of fruit and by the average size of apples. These studies suggest that the influence of semantic knowledge on current task performance might be more prevalent than previously thought. The results also suggest that the more inaccurate the STM for an experience or some information, the more we will resolve to use LTM to "fill the gaps." In contrast, when STM is accurate (e.g., in primacy and recency positions), then LTM plays less of a role (Heussen et al., 2011). The ubiquity of this influence of LTM raises the question whether we remember our own preferences or we construct them from the norms we have experienced. Do I really prefer skiing on prepared slopes to off-piste snowboarding or is it just what one is supposed to prefer, given a certain age and responsibility? Further, decisions about a just-experienced event can be very different depending on the accuracy of our memory over the short term - and how much it needs to rely on LTM.

Recent evidence has indicated that people do not have stable preferences for risk-taking, far from it. Many factors can influence the extent of one's tendency to take risky decisions; these include framing, accessibility in memory, and context among others (e.g., Kusev et al., 2009). Regarding the latter, a recent study has shown that people's risk preferences in financial settings were sensitive to context, i.e., to financial domain (Vlaev et al., 2010). The valence and complexity of the financial scenario influenced participants' decisionmaking. Risk preferences were stable within financial domains - e.g., positive (salary, gamble to win), negative (gamble to lose and insurance) and positive-complex domain (investment and mortgage) - but not across them. Participants did not display stable risk preferences; rather, they were largely influenced by the financial scenario at hand.

In conclusion, the evidence reviewed here suggests that although memory is clearly involved in the processes of judgments and 
decision, memory cannot be a good candidate to provide the stability of preferences. On the contrary, situational and contextual factors heavily influence memory processes and hence lead to unstable preferences. If preference stability does exist, memory is certainly not its basis.

\section{ACKNOWLEDGMENT}

This research was supported by the ESRC grant RES-062-23-2462.

\section{REFERENCES}

Aldrovandi, S., Poirier, M., Heussen, D., and Ayton, P. (2009). "Memory strategies mediate the relationships between memory and judgment," in Proceedings of the 31st Annual Conference of the Cognitive Science Society, eds N. A. Taatgen and H. van Rijn (Austin, TX: Cognitive Science Society), 2457-2462.

Aldrovandi, S., Poirier, M., Kusev, P., Heussen, D., and Ayton, P. (2011). "Now I like it, now I don't: delay effects and retrospective judgment," in Proceedings of the 33rd Annual Conference of the Cognitive Science Society, eds L. Carlson, C. Hoelscher, and T. F. Shipley (Austin, TX: Cognitive Science Society), 2866-2871.

Baines, C. J., To, T., and Wall, C. (1990). Women's attitudes to screening after participation in the National Breast Cancer Screening Study: a questionnaire survey. Cancer 65, 1663-1669.

Bedell, S.E., Delbanco, T. L., Cook, E. F., and Epstein, F. H. (1983). Survival after cardiopulmonary resuscitation in the hospital. N. Engl. J. Med. 309, 569-576.

Betsch, T., Plessner, H., Schwieren, C., and Gütig, R. (2001). I like it but I don't know why: a value-account approach to implicit attitude formation. Pers. Soc. Psychol. Bull. 27, 242-253.

Birnbaum, M. H. (2008). Evaluation of the priority heuristic as a descriptive model of risky decision making: comment on Brandstätter, Gigerenzer, and Hertwig (2006). Psychol. Rev. 115, 253-262.

Bjork, R.A., and Whitten, W. B. (1974). Recency-sensitive retrieval processes in long-term free recall. Cogn. Psychol. 6, 173-189.

Brainerd, C. J., and Reyna, V.F. (1992). Explaining "memory-free" reasoning. Psychol. Sci. 3, 332-339.

Brandstätter, E., Gigerenzer, G., and Hertwig, R. (2006). The priority heuristic: making choices without tradeoffs. Psychol. Rev. 113, 409-432.

Brehm, J.W. (1956). Post-decision changes in the desirability of alternatives. J. Abnorm. Soc. Psychol. 52,384-389.

Dougherty, M. R. P., Gettys, C. F., and Ogden, E. E. (1999). MINERVA-DM: a memory processes model for judgments of likelihood. Psychol. Rev. 106, 180-209.
Elwood, M., McNoe, B., Smith, T., Bandaranavake, M., and Doyle, T.C. (1998). Once is not enough: why some women do not continue to participate in a breast cancer screening programme. N. Z. Med. J. 111, 180-183.

Festinger, L. (1957). A Theory of Cognitive Dissonance. Evanston, IL: Row \& Peterson.

Hastie, R., and Park, B. (1986). The relationship between memory and judgement depends on whether the judgment task is memory-based or on-line. Psychol. Rev. 93, 258-268.

Hemmer, P., and Steyvers, M. (2009). Integrating episodic memories and prior knowledge at multiple levels of abstraction. Psychon. B Rev. 16, 80-87.

Henkel, L. A., and Mather, M. (2007). Memory attributions for choices: how beliefs shape our memories. J. Mem. Lang. 57, 163-176.

Heussen, D., Poirier, M., Hampton, J.A., and Aldrovandi, S. (2011). "An effect of semantic memory on immediate memory in the visual domain," in European Perspectives on Cognitive Science: Proceedings of the European Conference on Cognitive Science, eds B. Kokinov, A. Karmiloff-Smith, and N. J. Nersessian (Sofia: NBU Press). Article No: 134.

Johansson, P., Hall, L., Sikström, S., and Olsson, A. (2005). Failure to detect mismatches between intention and outcome in a simple decision task. Science 310, 116-119.

Kahneman, D. (2000). "Evaluations by moments: past and future," in Choices, Values and Frames, eds D. Kahneman and A. Tversky (New York: Cambridge University Press), 693-708.

Kahneman, D., Fredrickson, B. L., Schreiber, C. A., and Redelmeier, D.A. (1993). When more pain is preferred to less: adding a better end. Psychol. Sci. 4, 401-405.

Kahneman, D., and Thaler, R. H. (2006). Utility maximization and experienced utility. J. Econ. Perspect. 20, 221-234.

Kahneman, D., and Tversky, A. (1979). Prospect theory: an analysis of decision under risk. Econometrica 47, 263-291.

Kemp, S., Christopher, D. B. B., and Furneaux, L. (2008). A test of the peak-end rule with extended autobiographical events. Mem. Cognit. 36, 132-138.

Kusev, P., van Schaik, P., Ayton, P., Dent, J., and Chater, N. (2009). Exaggerated risk: prospect theory and probability weighting in risky choice. J. Exp. Psychol. Learn. Mem. Cogn. 35, 1487-1505.

Langer, T., Sarin, R. K., and Weber, M. (2005). The retrospective evaluation of payment sequences: duration neglect and peak-and-end effects. J. Econ. Behav. Organ. 58, 157-175.

LeDoux, J. E. (1996). The Emotional Brain. New York Simon \& Schuster.

LeDoux, J. E. (2002). Synaptic Self: How Our Brains Become Who We Are. New York: Viking.
McDermott, K. B., and Watson, J. M. (2001). The rise and fall of false recall: the impact of presentation duration. J. Mem. Lang. 45, 160-176.

Norman, K.A., and Schacter, D. L. (1997). False recognition in younger and older adults: exploring the characteristics of illusory memories. Mem. Cognit. 25, 838-848.

Redelmeier, D. A., Katz, J., and Kahneman, D. (2003). Memories of colonoscopy: a randomized trial. Pain 104, 187-194.

Roediger, H. L., and McDermott, K. B. (1995). Creating false memories: remembering words not presented in lists. J. Exp. Psychol. Learn. Mem. Cogn. 21, 803-814.

Schwarz, N., and Vaughn, L. A. (2002). “The availability heuristic revisited: ease of recall and content of recall as distinct sources of information," in Heuristic and Biases, eds T. Gilovich, D. Griffin, and D. Kahneman (New York: Cambridge University Press), 103-119.

Shafir, E., Simonson, I., and Tversky, A. (1993). Reasonbased choice. Cognition 49, 11-36.

Soman, D. (2003). Prospective and retrospective evaluations of experiences: how you evaluate it depends on when you evaluate it. J. Behav. Decis. Mak. 16, 35-52.

Stewart, N., Chater, N., and Brown, G. D. A. (2006). Decision by sampling. Cogn. Psychol. 53, 1-26.

Tversky, A., and Kahneman, D. (1992). Advances in prospect theory: cumulative representation of uncertainty. J. Risk Uncertain 5, 297-323.

Tversky, A., and Koehler, D. J. (1994). Support theory: a nonextensional representation of subjective probability. Psychol. Rev. 101, 547-567.

Vlaev, I., Kusev, P., Stewart, N., Aldrovandi, S., and Chater, N. (2010). Domain effects and financial risk attitudes. Risk Anal. 30, 1374-1386.

von Neumann, J., and Morgenstern, O. (1947). Theory of Games and Economic Behaviour, 2nd Edn. Princeton, NJ: Princeton University Press.

Weber, E. U., and Johnson, E. J. (2006). "Constructing preferences from memory," in The Construction of Preferences, eds S. Lichtenstein and P. Slovic (New York: Cambridge University Press), 397-410.

Received: 01 July 2011; accepted: 11 October 2011; published online: 15 November 2011

Citation: Aldrovandi S and Heussen D (2011) Preference stability and memory: two unlikely companions. Front. Psychology. 2:291. doi: 10.3389/fpsyg.2011.00291

This article was submitted to Frontiers in Cognition, a specialty of Frontiers in Psychology.

Copyright $\odot 2011$ Aldrovandi and Heussen. This is an openaccess article subject to a non-exclusive license between the authors and Frontiers Media SA, which permits use, distribution and reproduction in other forums, provided the original authors and source are credited and other Frontiers conditions are complied with. 